\title{
Modelling Manufacturing System Controller-based Siphon Petri Nets
}

\author{
Mowafak Hassan Abdul-Hussin
}

Al-Taff University College, Dept. of Computer Technical Engineering, Karabla, IQ

Received: 31 March 2020; Accepted: 13 May 2020; Published: 08 June 2020

\begin{abstract}
This work is focused on the deadlock prevention problem for a class of Flexible Manufacturing Systems(FMSs) which is modelled by Systems of Simple Sequential Processes with Resources ( $\left.\mathrm{S}^{3} \mathrm{PRs}\right)$, based on Petri net models. Petri Nets (PNs) gives a strong framework of modelling resources shared between concurr-ent processes in FMSs. This paper deals design methodology of controllers based on the Petri nets for the synthesis of FMSs based on a siphon PNs analysis is to be controlled by the set of minimal siphons which are generate a new P-Semifiow. We distinguish siphons in PN to give the necessary impact on the final supervisor control scheme that is the basis siphon structure analyzed to control FMS. The experimental approach is Siphon PN to give an effective tool for the liveness network, which gives a typical analysis to solve deadlock prevention in FMSs models are checked by PNs. Successful implementation of an FMS corresponds to synthesize a PN is to compute process models in parallel systems that have been specified to deadlock detection. In our application, the examples of an FMS are a control system by PN.
\end{abstract}

Index Terms: Siphons, Experimental approaches, FMS, Petri Net-Toolbox V. 2.3, Simulation

(C) 2020 Published by MECS Publisher. Selection and/or peer review under responsibility of the Research Association of Modern Education and Computer Science

\section{Introduction}

An FMS is advanced technologies manufacturing facility processes of the high flexibility to useful reso-urce allocation and part routing, and event-driven operation. Generally, an FMS consists of several work-station exhibit a high degree of resource sharing, and competing for finite resources use to control the activities of several pieces of manufacturing equipment (e.g. machines, robots, buffers, AGVs', etc). In the general setting the parts advancing through the system compete for a finite number of resources, a deadlock may happen. Limited shared resources are a competition between them it leads to sharing resources systems, Circular Waits,

* Corresponding author

E-mail address: mow.abdulg@gmail.com 
resource-circuits, and deadlock in FMS $[1,2]$. In an exemplary FMS, raw parts of different types enter the system at factors of time or asynchronously [3, 4, 5] processed and simultaneously [6], and concurrently interacting recursively processes sharing common resources lead to a deadlock or blocking. The former is used for representation of PN, and solving deadlock prevention that is a very important issue in[7-13] essence for FMS. Petri Net property siphons lead to an unmarked please net which is modelled concurrent systems have to deal with the satisfaction of the conditions of good behaviour in the multi-resources in the distributed systems. Row et al., [14] developed a new approach that is appropriate to all $\mathrm{S}^{3} \mathrm{PR}$ models of FMS. The liveness Petri net can achievable by only controlling elementary siphons.

One way of choosing with deadlock problems is to model an FMS with Petri nets $[27,28]$. The pioneer approaches using Petri net techniques to cope with deadlocks in FMS are mainly implemented by preventing some necessary conditions or detect and resolve a deadlock when it occurs. Petri Net is a versatile hierarc-hical modelling tool combination of a large class of the model of a manufacturing system that represent in production, industrial, and social systems can be regarded as large-scale discrete optimization problems [18], [19]. In the formulation and synthesis of Petri_net use invariance properties that can be automatically computed, help to build the controller [5-9] should be able to ensure the property, i.e., the siphon is generated. The dynamics controlling of FMS are developing actually based on the characteristic structure of $S^{3} \mathrm{PR}$ net, and the existing deadlock prevention problem is solved using the concept of siphon-based policies and reachabilitygraph-based. The declarative models employing, the multimodal routes planning that aims to find an optimal route between the resource, where Petri_Net to the evaluation of many interesting models such as modelled on FMS, Computer Networks, programming models, and Model-Based Testing.

The Large-Scale systems of FMS [15-18], are difficult to model commonplace is described by Petri nets techniques using in the information system design process. As a result, an alternative sequence is a separation or division into suitable numbers of interconnected sub-systems to reduce their complexity of modeling resource allocation tasks [19]. Modelling and simulation [20-24] are very important techniques of decision making on the stage of the complex system designing. The aimed behavioural specification PN is the evaluation of application-specific a class $\mathrm{S}^{3} \mathrm{PR}$ at the system of FMS modelling and control distributed system, where multiple processes and resources are executed concurrently and/or asynchronous. In spite of the fact that reachability-graph-based approaches [25], can generally to ensure the optimality or suboptimality of the controlled framework as far as shows the distributed systems. The existing approaches to measuring FMS are Petri nets have well-known properties over other models which are demonstrated to be a tool for prominent capabilities to describe FMS. Abdul-Hussin et al., [9, 10] describe a simulations PN by Matlab in order to show that the reachability graph and total computational are required to investigate the deadlock that siphons analyses can be utilized to determine if deadlock markings are reachable.

The simulation results provided with a visualization Petri net model of FMSs are developing methods of the optimization that can be improved on siphons based on the controller exhibits to be the best performance of the sequence operations manufacturing systems $[5,6,7]$. The circular waits are deadlocks occurrences of FMS which are related to specified resource allocations request. Petri_Net provides the power of automatic construction of an entire PN based controllers of a manufacturing workstation [9-13]. Moreover, the reachability graph can already be analyzed a generally presupposes a complete of reachable states [23, 24, 30]. Among the existing modeling formalisms, Petri nets emerge because of its characteristics is implemented to the literature for types modeling of production systems. This paper presents the general characteristics widespread used so-called S ${ }^{3}$ PR (i.e. Systems of Simple Sequential Processes with Resources)[15], which is actually adopting PNs as the design technique for controlled automation system. The concept of siphons used to be extended subsequently by $\mathrm{Li}$ et al., $[16,17]$.

Our approach is the dynamic simulation of interpreted adaptive Siphons PN under supervision are required to be sufficiently marked at any reachable marking from an initial marking. Petri Nets were used in [9, 10], employs deadlock prevention based on the structure siphons analyzed, and reachability graphs PNs are used to a class so-called $\left.\left(\mathrm{S}^{4} \mathrm{PR}\right)\right\}[20,21,30]$, to compute emptiable minimal or maximal siphons in marked Petri nets. These contributions have Petri Nets as a powerful modeling tool for the components of FMS that have been 
successfully used for such analyses. These studies deal with $S^{4} P R$, which is a generalization of $S^{3} P R$ nets, and extend $S^{3} P R$ nets to model the complexity such a system showed by using alternative resources [19, 29], as in $\mathrm{S}^{3} \mathrm{PR}$ nets, are exploiting many resources simultaneously. Place Invariants (PI) are applied to control deadlock prevention in [20-25] FMS.

As above mentioned, it has already been a simulation approach [20, 21], which is another effective method of analyzed deadlock and Reachability Graph (RG) is deciding for a given marking $M$, whether it is reachable in a specific net. It is PN simulated with the tool Matlab [5-7], which is critical to high-lights the fact that considerable control issues with FMS in [9-13]. Petri_Nets has an advantage of appropriate methods of efficient tools, and implementation to ensure the uninterrupted functioning of the plant net model that is originally built.

Organization. Section II, reviews some basics of Petri nets used throughout this paper. The prerequisite for the concepts of siphons is presented, and The computation of a control place by a P-Semifiow in Section III. Section IV, recalls the results of an $\mathrm{S}^{3} \mathrm{PR}$-net presents the results of simulation then conclusion.

\section{Preliminaries}

\subsection{Petri Net [15-20]}

A PN is a 4-tuple $\mathrm{G}=(\mathrm{P}, \mathrm{T}, \mathrm{Q}, \mathrm{W})$ where $\mathrm{P}$ and $\mathrm{T}$ are finite and nonempty sets. $\mathrm{P}$ is a set of places and $\mathrm{T}$ is a set of "transitions" with $\mathrm{P} \cup \mathrm{T} \neq \varnothing$, and $\mathrm{P} \cap \mathrm{T}=\varnothing . \mathrm{Q} \subseteq(\mathrm{P} \times \mathrm{T}) \cup(\mathrm{T} \times \mathrm{P})$ is called a flow relation represented by directed arcs. $\mathrm{W}:(\mathrm{P} \times \mathrm{T}) \cup(\mathrm{T} \times \mathrm{P}) \rightarrow\{0,1\}$ is a mapping that assigns a Weight to an агс.

A node of $x$ in $G=(P, T, Q)$ is either a $p \in P$ or $t \in T$. The post-set of node $x$ is $x \bullet=\{y \in P \cup T \mid(y, x) \in Q\}$, and its pre-set $\bullet x=\{y \in P \cup T \mid(y, x) \in Q\}$. Where $W(x, y)>0$ if $(x, y) \in Q$, and $W(x, y)=0$ otherwise, where $\mathrm{x}, \mathrm{y} \in \mathrm{P} \cup \mathrm{T}$. If $\mathrm{W}(\mathrm{x}, \mathrm{y})=1, \forall(\mathrm{x}, \mathrm{y}) \in \mathrm{Q}$. The net $\mathrm{G}$ is called an ordinary Petri Net (OPN, for short), indicated by $\mathrm{G}=(\mathrm{P}, \mathrm{T}, \mathrm{Q})$ if $\forall \mathrm{q} \in \mathrm{Q}, \mathrm{W}(\mathrm{q})=1$. An $\mathrm{OPN}$ is called a state machine (SM) if $\forall \mathrm{t} \in \mathrm{T},|\bullet t|=|t \bullet|=1$. A marking is a mapping $\mathrm{M}: \mathrm{P} \rightarrow \check{Z}$, where $\breve{Z} \cup\{0\}$. M(p) denotes the number of tokens in place p. A pair (G, $\mathrm{M}_{0}$ ) is called a marked Petri_Net or a net system, and $\mathrm{M}_{0}$ is called an initial-marking of $\mathrm{G}$. The set of markings reachable from $\mathrm{M}$ in $\mathrm{G}$ is denoted as $\mathrm{R}\left(\mathrm{G}, M_{0}\right)$. For a set of places $S \subseteq P$ the marking of place $\mathrm{S}$ is defined as: $M(S)=\sum p \in S M(p)$ is used to define a vector M. Petri_Net will be described either by the pair $G=\left(G, M_{0}\right)$, where $\mathrm{G}$ is a $\mathrm{PN}$, and $\mathrm{M}_{0}$ is initial marking, or by 5 -tuple: $\mathrm{G}=\left(\mathrm{P}, \mathrm{T}, \mathrm{Q}, \mathrm{W}, \mathrm{M}_{0}\right)$.

For all siphon $S \subseteq P$, is a siphon if and only if (iff) ${ }^{\circ} S \subseteq S^{\bullet}$. A siphon is called minimal if it doesn't contain any other siphon. A minimal siphon that does not contain the support of any P-Semifiow is called Strict Minimal Siphons (SMSs, for short). For a structurally bounded net, $\mathrm{B}(\mathrm{p})$ is the structural bound of place $\mathrm{p}$, where $\mathrm{B}(\mathrm{p})=\max \left[\mathrm{M}(\mathrm{p}) \mid \mathrm{M}=\mathrm{M}_{0}+[\mathrm{G}] \cdot \mathrm{Y} ; \mathrm{M} \geq 0 ; \mathrm{Y} \geq 0\right]$.

Definition 1: A P-Semifiow (T-Semifiow) is a vector $X \geq 0$, and $(Y \geq 0)$ such that $C^{T} \cdot X^{T}=0,\left(Y^{T} \cdot C^{T}=0\right)$, also called conservative components. The P-invariant is said to be a P-Semifiow if non number of $\mathrm{I}$ is negative. A P-invariant $I$ is said to be a P-Semifiow for all the element of $I$ is non-negative. A P-Semifiow $I$ is minimal if the greatest common devisor of its non-zего components is $I$ and $\|I\|$ is not a included another set of the backup of any other P-Semifiow. We use $\sigma$ represents a firing sequence, while $\sigma$ ' is the firing count vector associated with $\sigma$. If $M$ is reachable from $M_{0}\{$ i.e. $\exists \sigma$ such that (s.t.) $M[\sigma\rangle M\}$, then $M=M_{0}+C \cdot \sigma^{\prime} \geq 0$, where $\mathrm{C}$ is matrix net, and $\sigma^{\prime} \geq 0$.

Definition 2. Let $\left(G, M_{0}\right)$ a marked in an $\mathrm{S}^{3} \mathrm{PR}$-net is conservative if for all $M \in R\left(G, M_{0}\right), \quad \sum_{\mathrm{pi}} \in \mathrm{P} \mathrm{M}\left(\mathrm{p}_{\mathrm{i}}\right)=$ $\sum_{\mathrm{pi}} \in \mathrm{P} \mathrm{M}_{0}\left(\mathrm{p}_{\mathrm{i}}\right)$. Conservation implies that the complete number of tokens is the equivalent for all markings reachable from $M$. 
Definition 3. A vector $x \in \mathrm{G}^{\mathrm{T}}$ is a $P$-invariants if $x \cdot C=0$, where $\mathrm{C}$ is matrix of $\mathrm{G}$. A $P$-invariants has advantage to the constancy of tokens in subsets of places.

Proposition 1. Let $\left(G, M_{0}\right)$ be a marked in an $\mathrm{S}^{3} \mathrm{PR}$, a P-Semifiow is characterized resource places are correlated with the resource places and their holders. The relationship P-Semifiow in an S PR is $\left|\mathrm{I}_{\mathrm{G}}\right|+\left|\mathrm{P}_{R}\right|$.

\subsection{A class of the S3PR Models by Petri Nets}

A formula expressing of definitions are adapted from [13]. The reader is referred to [13] for more details of the $S^{3} P R$ model in [29].

Definition 4. $[15,16]$ Let $I_{\mathrm{G}}$ be a finite set of indices, an $\mathrm{S}^{3} \mathrm{PR}$ is a Petri net $\mathrm{G}=\left(P_{\mathrm{A}} \cup P_{0}, P_{\mathrm{R}}, T, Q\right)$, defined as the union of a set of nets $\mathrm{G}=\left(P_{\mathrm{Ai}} \cup P_{0 \mathrm{i}}, P_{\mathrm{Ri}}, T_{i}, Q_{\mathrm{i}}\right), \quad\left(\mathrm{i} \in \mathrm{N}_{\mathrm{n}}=\{1,2, \ldots, n\}\right)$ sharing common places.

1) $\mathrm{P}=\mathrm{P}_{\mathrm{A}} \cup \mathrm{P}_{\mathrm{R}} \cup \mathrm{P}_{0}$ is a partition such that:

a) $P_{0}=\left\{P_{0}^{1}, \ldots, P_{0}^{k}\right\}, \mathrm{K}>0, \mathrm{p} \in \mathrm{P}_{0}$ is called an idle place;

b) $P_{A}^{i}=\bigcup_{i=1}^{k} P_{A}^{i}$, where $\forall i \neq j, P_{A}^{i} \cap P_{A}^{j}=\varnothing, \quad\left(p \in P_{A}^{i}\right)$ is called an Activity place;

c) $P_{R}=\left\{r_{1}, \ldots, r_{n}\right\}, n>0\left(r \in P_{R}\right.$ is called resource place $)$;

2) $\mathrm{T}=\bigcup_{i=1}^{k} \mathrm{~T}^{i}$, where $\forall \mathrm{i} \neq \mathrm{j} \mathrm{T}^{i} \cap \mathrm{T}^{j}=\varnothing$;

3) $\forall \mathrm{i} \in \mathrm{G}^{\mathrm{i}}$ the subnet $\mathrm{G}^{\mathrm{i}}$ generated by $\left\{p_{0}^{i}\right\} \cup \mathrm{P}_{A}^{i} \cup \mathrm{T}^{i}$, is strongly connected state machine, for instance, every circle contains $\left\{p_{0}^{i}\right\}$, and $\left(\mathrm{G}^{\mathrm{i}}\right.$ is called a simple sequential process $\left.\left(S^{2} P\right)\right)$;

4) G is strongly connected.

5) $\forall i \in \mathrm{I}_{\mathrm{N}}, \forall p \in \mathrm{P}_{A}^{i}, \ddot{p} p \cap \mathrm{P}_{R}=p \cdot \bullet \mathrm{P}_{R}$ and $\left|{ }^{\bullet} p \cap \mathrm{P}_{R}\right|=1$.

Definition 5. Let $\mathrm{G}=\left(P_{S} \cup P_{R} \cup P^{0}, T, Q\right)$ be an $\mathrm{S}^{3} \mathrm{PR}$. An initial marking $M_{0}$ is called acceptable if:

1) $\left.\left.M_{0}(\mathrm{p}) \geq 1, \forall p \in P_{R} ; 2\right) M_{0}(p)=0, \forall p \in P_{A} ; 3\right) M_{0}(p) \geq 1, \forall p \in P^{0}$.

Definition 6. Let $S$ be a siphon in an $\mathrm{S}^{3} \mathrm{PR}$. For $\mathrm{r} \in \mathrm{P}_{\mathrm{R}}, \mathrm{H}(\mathrm{r})={ }^{\bullet}{ }^{\mathrm{r}} \cap \mathrm{P}_{\mathrm{A}}$, the activity places that use $\mathrm{r}$, is called the set of holders of $\mathrm{r}$. Let $[S]=\left(\bigcup_{r \in S} H(r)\right) \backslash S$. Note that any resource $\mathrm{r} \in P_{R}$ is correlating with a minimal P-Semifiow $\mathrm{I}_{r}$ s.t. $\left\|\mathrm{I}_{\mathrm{r}}\right\|=\{\mathrm{r}\} \cup \mathrm{H}(\mathrm{r})$. Any $p \in P_{A_{i}}$ is correlating with a minimal P-Semifiow $\mathrm{I}_{\mathrm{p}}$ with support $\left\|\mathrm{I}_{p}\right\|=P_{A_{i}} \cup\left\{P_{i}^{0}\right\}$.

\section{Elementary and Dependent Siphons}

The idea siphons and an $S^{3} \mathrm{PR}[17,18]$ that will be used it.

Definition 7. Let $\mathrm{S} \subseteq \mathrm{P}$ be a subset of places of $\mathrm{G}$. A P-vector $\lambda_{\mathrm{S}}$ is defined the distinctive P-vector of $\mathrm{S}$ if $\forall p \in S, \lambda_{\mathrm{S}}(p)=1$; otherwise $\lambda_{\mathrm{S}}(p)=0$.

Definition 8. Let $\mathrm{S}$ be a subset of places of $\mathrm{G}$ and $\eta_{s}$ is distinctive by T-vector of S if $\eta_{S}^{T}=\lambda_{S}^{T} \bullet[G]$.

Definition 9. Let $\mathrm{G}=(\mathrm{P}, \mathrm{T}, Q)$ be a net with $|\mathrm{P}|=\mathrm{m},|T|=\check{\mathrm{n}}$, and $\check{Z}$ siphons, $\breve{\mathrm{S}}_{1}, \breve{\mathrm{S}}_{2}, \ldots$, and $\check{\mathrm{S}}_{\check{Z}}$, ḿ, $\check{\text { n̆}}, \check{Z} \in$ 
G. Consider $\lambda_{\mathrm{Si}}\left(\dot{\eta}_{\mathrm{Si}}\right)$ be the distinguishing by $P(T)$-vector of siphon $\mathrm{S}_{\mathrm{i}}, \mathrm{i} \in 1-\check{\mathrm{Z}}$ \}. Note that, the realization of

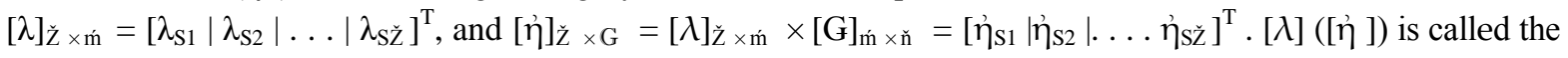
distinguishing by $P(T)$-vector matrix of the siphons in $\mathrm{G}$.

Lemma 1. Let $\left(G, M_{0}\right)$ be a marked in an $S^{3} P R$. The Siphon $S$ in G is:

(1) $\mathrm{S}$ don't have marked iff $\exists M^{\prime} \in \underline{\mathrm{R}}\left(G, M_{0}\right)$, that is $\mathrm{M}(\mathrm{S})=0$, where siphon $\mathrm{S}$ is emptied.

2) P-invariant is controlled $G$ when $S$ cannot be empty.

3) A siphon acquires its activity when is emptied.

Proposition 2: The invariant-controlled PN is controlled a siphon S [15].

Proposition 3: $[9,10,11]$. Let $\left(G, M_{0}\right)$ be a Petri net and $\mathrm{S}$ be a siphon of G.

If there exists a P-invariant $I$ is said to be a P-Semifiow if $\forall \mathrm{I}$, is non-negative, $\forall \mathrm{p} \in\left\{\|I\| \|^{-} \cap \mathrm{S}\right\}$, where $\max _{p}=1,\|I\|^{+} \in \mathrm{S}$, if $I^{\mathrm{T}} \bullet \mathrm{M}_{0}>\sum_{\mathrm{p} \in \mathrm{S}} I(p)\left(\max _{p} \cdot-1\right)$, then $\mathrm{S}$ is max-controlled.

Lemma 2. The set of elementaгу siphons (ESs) in net G equals to the rank [ $\eta]$ [17].

Theorem 1. Let $\mathrm{G}_{\mathrm{ES}}$ is referring to $\mathrm{ESs}$ in $\mathrm{G}=\left({ }^{\circ} \mathrm{P}, \mathrm{T}, \mathrm{Q}\right)$.

The formula is representing by: $\mathrm{G}_{\mathrm{ES}}<\min \{|\mathrm{P}|,\{|\mathrm{T}|\}$.

Theorem 2. Let $\mathrm{S}$ be a siphon if the net $\mathrm{G}=(\mathrm{P}, \mathrm{T}, \mathrm{Q})$, and $\eta_{\mathrm{S}}$ be its discriminatory $\mathrm{T}$-vector. We can define that $\left\{t \in \mathrm{T} \mid \eta_{\mathrm{S}}(t)>0\right\},\left\{t \in \mathrm{T} \mid \eta_{\mathrm{S}}(t)=0\right\}$, and $\left\{t \in T \mid \eta_{\mathrm{S}}(t)<0\right\}$ are a set of transitions.
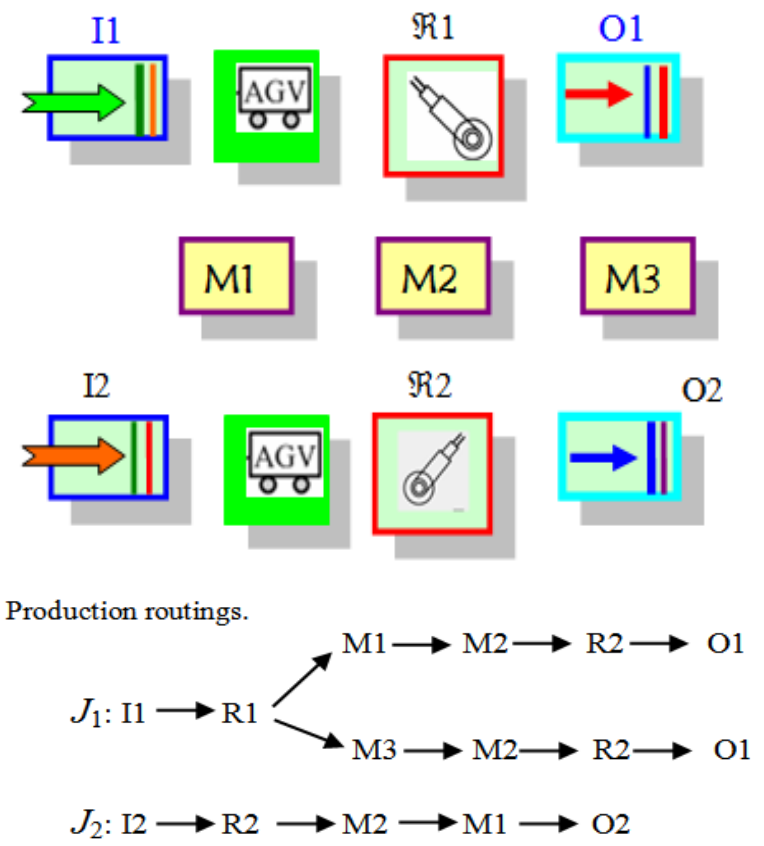

Fig. 1. Production cell 
Example'1. An FMS model involves two working processes (WP) competing for resources with two models sequence of operations. Considering the model routings represented in Fig. 1, that has three state machines "M1-M3", which uses two types of robots $\mathfrak{R} 1$, and $\mathfrak{R} 2$; are required during several parts of the process presents of an $\mathrm{S}^{3} \mathrm{PR}$ net. $\Re 1$ handles part movements towards produced $\mathrm{P} 1$, and $\mathrm{P} 2$ type according to production Routings shown in Fig. 1. Parts enter the cell during two loadings buffeгs $\mathrm{I}_{1}$, and $\mathrm{I}_{2}$, and leave the cell over two unloading buffers O1, and O2. Our proposed method contains two Production line part types of jobs $\left(J_{1}, J_{2}\right)$ are executed components in a typical of FMS, where the Parts enter it. The appearance of Fig. 2, PN modelled on the FMS, indicated by $\left(G, M_{0}\right)$. It shows the system FMS example use case diagram to validate in the methodology.

A net $\left(G, M_{0}\right)$ shown in Fig. 2. For instance, the Petri net is an $S^{3} P R$ if $P^{0}=\left\{p_{60}, p_{70}\right\}$ is the set of idle places, $p_{1}^{A}=\left\{\mathrm{p}_{61}, \mathrm{p}_{62}, \mathrm{p}_{63}, \mathrm{p}_{64}\right\}$, is the set of operation places first, $p_{2}^{A}=\left\{\mathrm{p}_{61}, \mathrm{p}_{64}, \mathrm{p}_{65}, \mathrm{p}_{66}\right\}$ is the set of operation places second, $p_{3}^{A}=\left\{\mathrm{p}_{71}, \mathrm{p}_{72}, \mathrm{p}_{73}, \mathrm{p}_{74}\right\}$, is the set of operation places third, and $p_{R}=\left\{\mathfrak{R}_{1}, \mathfrak{R}_{2}\right.$, M1$\mathrm{M} 3\}$ is the set of shared resource places. Each operation place in $\mathrm{S}^{3} \mathrm{PR}$ can synchronous and simultaneously require multiple units of different resource types.

The $S^{3} \mathrm{PR}$ net model consists of two parallel sequential processes as shown in Fig. 2, that is, process 1: $p_{1}^{A}$ $=\left\{\mathrm{p}_{61}-\mathrm{p}_{64}\right\}$ is first, process 2: $p_{2}^{A}=\left\{\mathrm{p}_{61}-\mathrm{p}_{66}\right\}$ is second, and process $3: p_{3}^{A}=\left\{\mathrm{p}_{71}-\mathrm{p}_{74}\right\}$ is third. The system demonstration is a synchronized, and parallel sequential competing of operations and represented by five resource places $\{\mathfrak{R} 1, \mathfrak{R} 2, \mathrm{M} 1-\mathrm{M} 3\}$. These competitions of the limited resources may lead to deadlocks on this model. This phenomenon must be prevented before it occurs by some effective appropriateness tools.

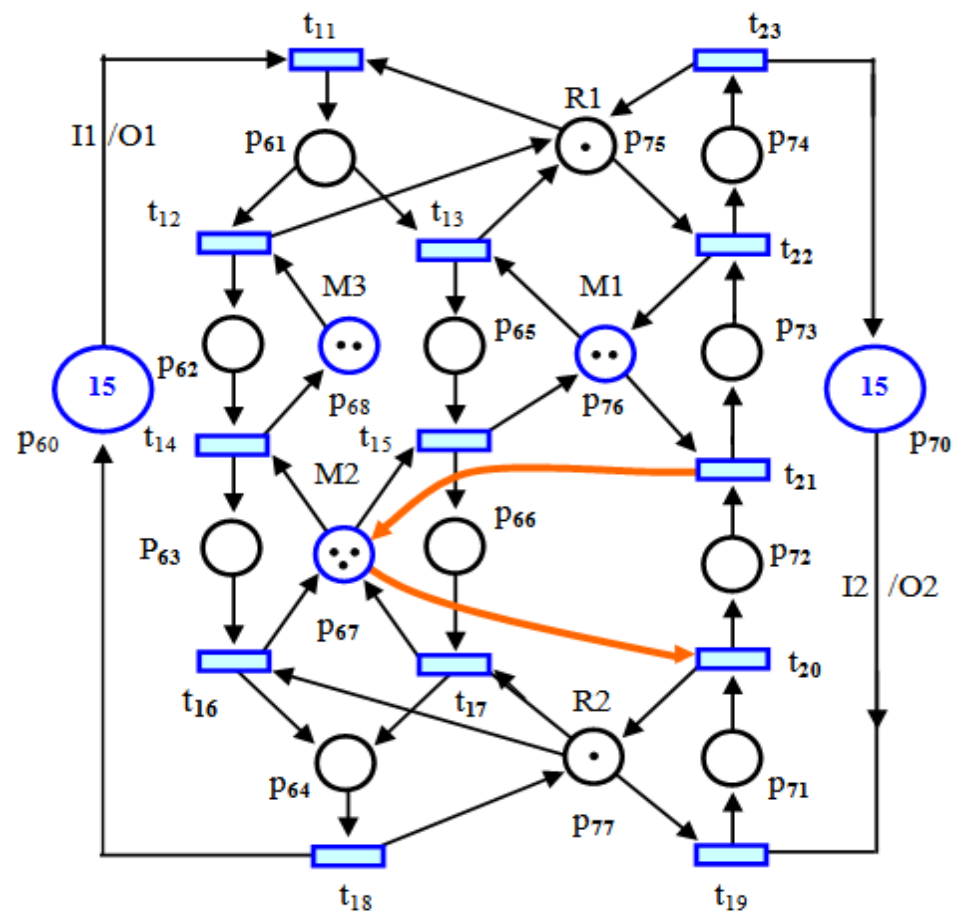

Fig. 2. Petri net model for an FMS cell with 2925 reachable states 
The net system is an $\mathrm{S}^{3} \mathrm{PR}$ net contains 29 deadlocks, with 2925 reachable states. In this system, have seven P-Semifiows taken from Fig. 2, as follow:

$$
I_{p 60}=p_{60}+p_{61}+p_{62}+p_{63}+p_{64}+p_{65}+p_{66}=15
$$

and

$$
\mathrm{I}_{\mathrm{p} 70}=\mathrm{p}_{70}+\mathrm{p}_{71}+\mathrm{p}_{72}+\mathrm{p}_{73}+\mathrm{p}_{72}+\mathrm{p}_{73}=15
$$

are the minimal P-Semifiows associated with idle places $\mathrm{p}_{60}$ and $\mathrm{p}_{70}$.

$$
\begin{gathered}
\mathrm{I}_{\mathrm{R} 1}=\mathrm{p}_{61}+\mathrm{p}_{74}+\Re 1=1, \mathrm{I}_{\mathrm{R} 2}=\mathrm{p}_{64}+\mathrm{p}_{71}+\Re 2=1, \mathrm{I}_{\mathrm{M} 1}=\mathrm{p}_{65}+\mathrm{p}_{73}+\mathrm{M} 1=1, \\
\mathrm{I}_{\mathrm{M} 2}=\mathrm{p}_{63}+\mathrm{p}_{66}+\mathrm{p}_{72}+\mathrm{M} 2=2, \text { and } \mathrm{I}_{\mathrm{M} 3}=\mathrm{p}_{62}+\mathrm{M} 3=2,
\end{gathered}
$$

are the minimal P-Semifiows associated with resources $\mathfrak{R} 1, \mathfrak{R} 2$, and $\mathrm{M} 1-\mathrm{M} 3$, respectively. Furthermore, an acceptable initial marking :

$$
\mathrm{M}_{0}=15 \mathrm{p}_{60}+15 \mathrm{p}_{70}+\mathfrak{R} 1+\mathfrak{R} 2+2 \mathrm{M} 1+3 \mathrm{M} 2+2 \mathrm{M} 3 .
$$

The net has four strict minimal siphons (SMSs):

$$
\mathrm{S}_{1}=\left\{\mathrm{p}_{64}, \mathrm{p}_{72}, \mathfrak{R} 2, \mathrm{M} 2\right\}, \mathrm{S}_{2}=\left\{\mathrm{p}_{64}, \mathrm{p}_{73}, \mathrm{M} 1, \mathfrak{R} 2, \mathrm{M} 2\right\} \text {, and }
$$

$\mathrm{S}_{3}=\left\{\mathrm{p}_{63}, \mathrm{p}_{66}, \mathrm{p}_{74}, \mathfrak{R} 1, \mathrm{M} 3, \mathrm{M} 1, \mathrm{M} 2\right\}$, and $\mathrm{S}_{4}=\left\{\mathrm{p}_{64}, \mathrm{p}_{74}, \mathfrak{R} 1, \mathrm{M} 3, \mathrm{M} 1, \mathfrak{R} 2, \mathrm{M} 2\right\}$

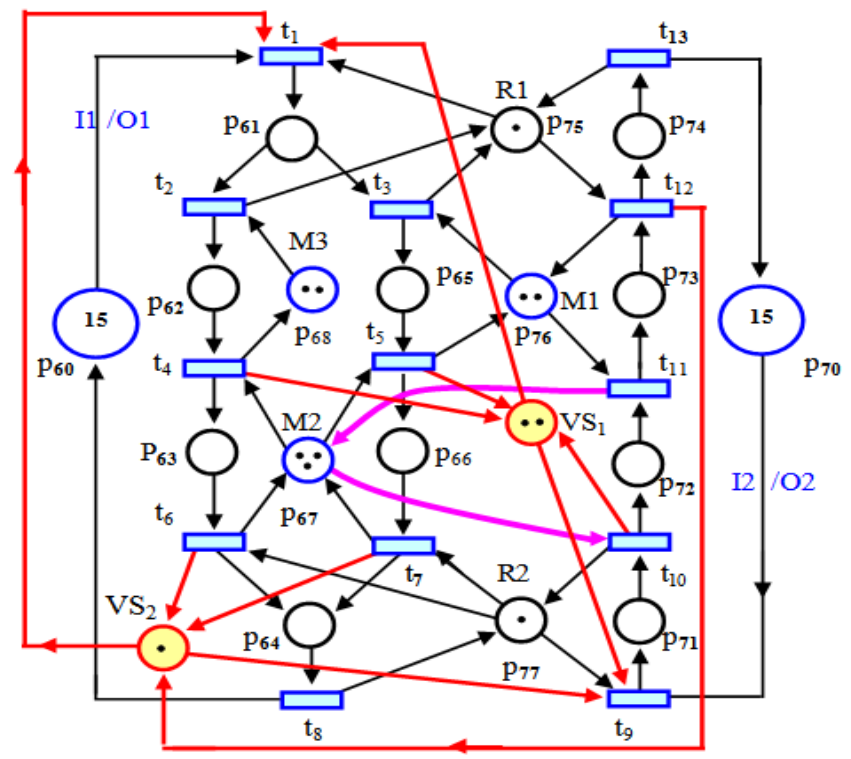

Fig. 3. Liveness enforcing supervisor for the FMS cell. 
The Petri_Net tool for the MATLAB [26] provides a powerful means for the model checking in the simulations in order to obtain the reachability graph (RG), and siphons calculated. In the calculation siphons in a PN, we use an emptiable siphon and imposes to monitor are added to prevent deadlock. Particularly, we distinguish two important elements of SMSs, which are evaluated as $\mathrm{S}_{1}, \mathrm{~S}_{2}$. A basic supervisory observation, problem consists of the controlled PN has no dead, marking and has 19 live markings.

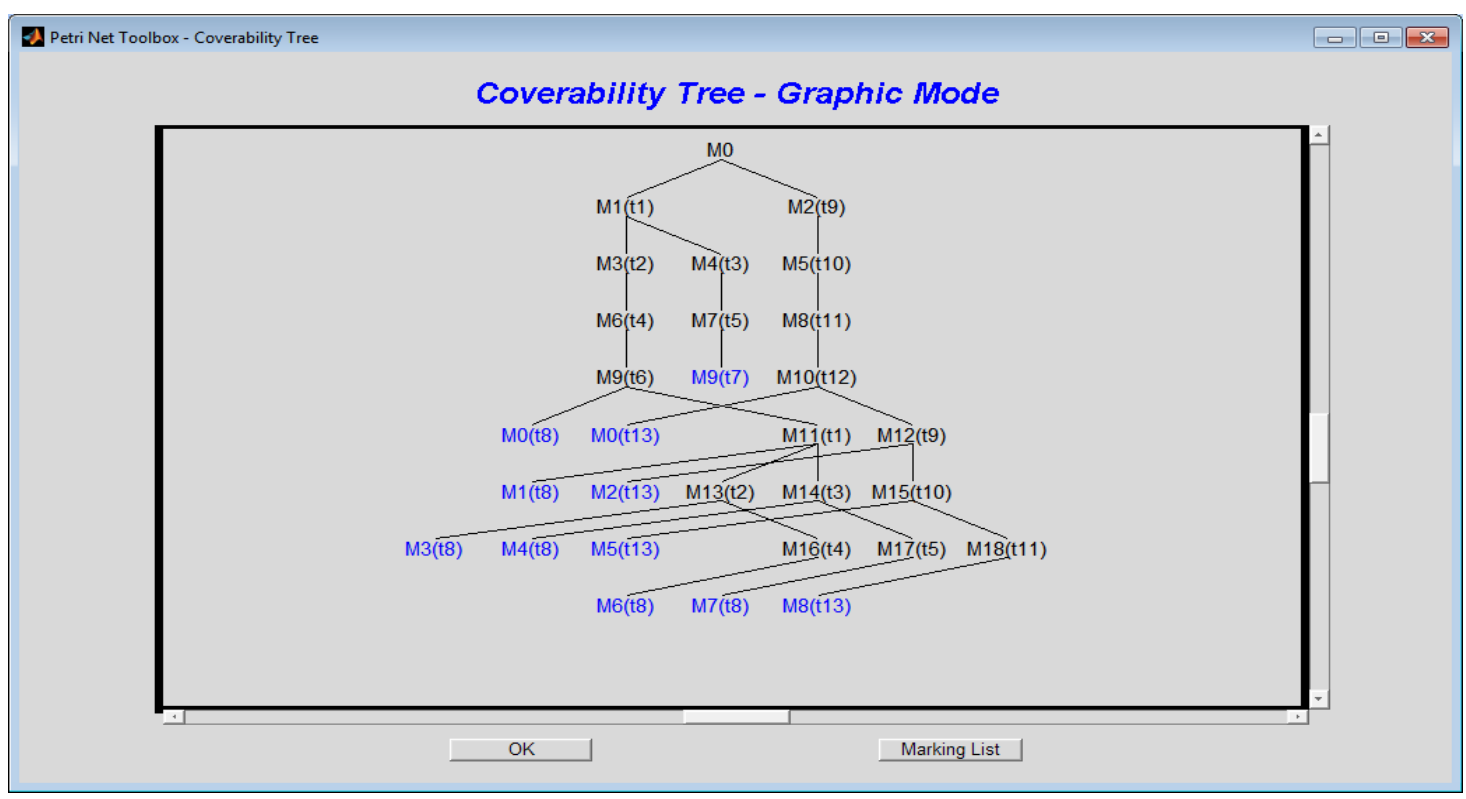

Fig. 4.Reachability graph of Fig. 3, is running in MATLAB, with two monitors VS1, and VS2.

\section{Simulation of FMS by Petri Nets}

Example 2. For illustration, the simulation Petri Net for an FMS model, let us consider the system shown in Fig. 5(A, and B), consisting of seven components. In fact, it should be needed to evaluate the PN model as describing the blocking situation which may occur to the synchronized process and/or competitive processes execution with the three robots R1-R3, and two machines M1 and M2 activity. Our proposed method contains two Production line part types of jobs $(J 1, J 2)$ that produce two types of production of FMS, where the Parts enter it. Petri Nets contains deadlock marked states.

By applying definition 6 , an acceptable initial marking $M_{0}=\left\{\mathrm{p}_{11}, \mathrm{p}_{12}, \mathrm{p}_{13}, \mathrm{p}_{14}, 6 \mathrm{p}_{15}, 6 \mathrm{p}_{16}, \mathrm{p}_{17}, \mathrm{p}_{21}, \mathrm{p}_{23}\right\}$. For instance, in Fig. 6, the net representation of an FMS is illustrated with marked $S^{3} P R$ G. In this system there are (15) SMSs that is accessible to the deadlock control purpose, where ESs are marked by $\breve{S}_{\mathrm{i}}$ :

$$
\begin{gathered}
S_{1}=\left\{\mathrm{p}_{2}, \mathrm{p}_{5}, \mathrm{M} 1, \mathrm{M} 4, \mathrm{R} 1, \mathrm{R} 2\right\}, \text { where } \mathrm{M}_{0}\left(S_{1}\right)=4 ; \\
S_{2}=\left\{\mathrm{p}_{6}, \mathrm{p}_{9}, \mathrm{M} 2, \mathrm{M} 3, \mathrm{R} 2, \mathrm{R} 3\right\} \text {, where } \mathrm{M}_{0}\left(S_{2}\right)=4 ; \\
S_{3}=\left\{\mathrm{p}_{2}, \mathrm{p}_{3}, \mathrm{p}_{7}, \mathrm{M} 1, \mathrm{M} 2, \mathrm{R} 1\right\}, \text { where } \mathrm{M}_{0}\left(S_{3}\right)=3 ; \\
\check{\mathrm{S}}_{4}=\left\{\mathrm{P}_{2}, \mathrm{P}_{3}, \mathrm{P}_{5}, \mathrm{M} 1, \mathrm{R} 1\right\} \text {, where } \mathrm{M}_{0}\left(\check{\mathrm{S}}_{4}\right)=2 ; \\
\check{\mathrm{S}}_{5}=\left\{\mathrm{p}_{1}, \mathrm{p}_{2}, \mathrm{p}_{7}, \mathrm{M} 2, \mathrm{R} 1\right\}, \text { where } \mathrm{M}_{0}\left(\check{\mathrm{S}}_{5}\right)=2 ; \\
\check{\mathrm{S}}_{6}=\left\{\mathrm{p}_{2}, \mathrm{p}_{9}, \mathrm{M} 1, \mathrm{M} 4, \mathrm{M} 2, \mathrm{M} 3, \mathrm{R} 1, \mathrm{R} 2, \mathrm{R} 3\right\}, \mathrm{M}_{0}\left(\check{\mathrm{S}}_{6}\right)=8 ;
\end{gathered}
$$


$\check{\mathrm{S}}_{7}=\left\{\mathrm{p}_{1}, \mathrm{p}_{2}, \mathrm{p}_{3}, \mathrm{p}_{7}, \mathrm{M} 2, \mathrm{R} 1\right\}$, where $\mathrm{M}_{0}\left(\check{\mathrm{S}}_{7}\right)=2$;

$\check{\mathrm{S}}_{8}=\left\{\mathrm{p}_{2}, \mathrm{p}_{3}, \mathrm{R} 1, \mathrm{M} 1\right\}$, where $\mathrm{M}_{0}\left(\check{\mathrm{S}}_{8}\right)=2$;

$\breve{\mathrm{S}}_{9}=\left\{\mathrm{p}_{2}, \mathrm{p}_{3}, \mathrm{p}_{4}, \mathrm{M} 1, \mathrm{M} 4\right\}$, where $\mathrm{M}_{0}\left(\check{\mathrm{S}}_{9}\right)=2 ; \check{\mathrm{S}}_{10}=\left\{\mathrm{p}_{1}, \mathrm{p}_{2}, \mathrm{p}_{3}, \mathrm{R} 1\right\}$, where $\mathrm{M}_{0}\left(\check{\mathrm{S}}_{10}\right)=1$;

$\breve{\mathrm{S}}_{11}=\left\{\mathrm{p}_{1}, \mathrm{p}_{2}, \mathrm{p}_{3}, \mathrm{p}_{5}, \mathrm{R} 1\right\}$, where $\mathrm{M}_{0}\left(\check{\mathrm{S}}_{11}\right)=1$;

$\check{\mathrm{S}}_{12}=\left\{\mathrm{p}_{2}, \mathrm{p}_{3}, \mathrm{p}_{4}, \mathrm{p}_{5}, \mathrm{M} 1, \mathrm{M} 4\right\}$, where $\mathrm{M}_{0}\left(\check{\mathrm{S}}_{12}\right)=2$;

$\check{\mathrm{S}}_{13}=\left\{\mathrm{p}_{2}, \mathrm{p}_{3}, \mathrm{p}_{4}, \mathrm{p}_{5}, \mathrm{p}_{7}, \mathrm{M} 1, \mathrm{M} 4\right\}$, where $\mathrm{M}_{0}\left(\check{\mathrm{S}}_{13}\right)=2$;

$\check{\mathrm{S}}_{14}=\left\{\mathrm{p}_{1}, \mathrm{p}_{2}, \mathrm{p}_{3}, \mathrm{p}_{5}, \mathrm{p}_{7}, \mathrm{R} 1\right\}$, where $\mathrm{M}_{0}\left(\check{\mathrm{S}}_{14}\right)=1$; and

$\check{\mathrm{S}}_{15}=\left\{\mathrm{p}_{2}, \mathrm{p}_{3}, \mathrm{p}_{5}, \mathrm{p}_{7}, \mathrm{M} 1, \mathrm{R} 1\right\}$, where $\mathrm{M}_{0}\left(\check{\mathrm{S}}_{15}\right)=2$.

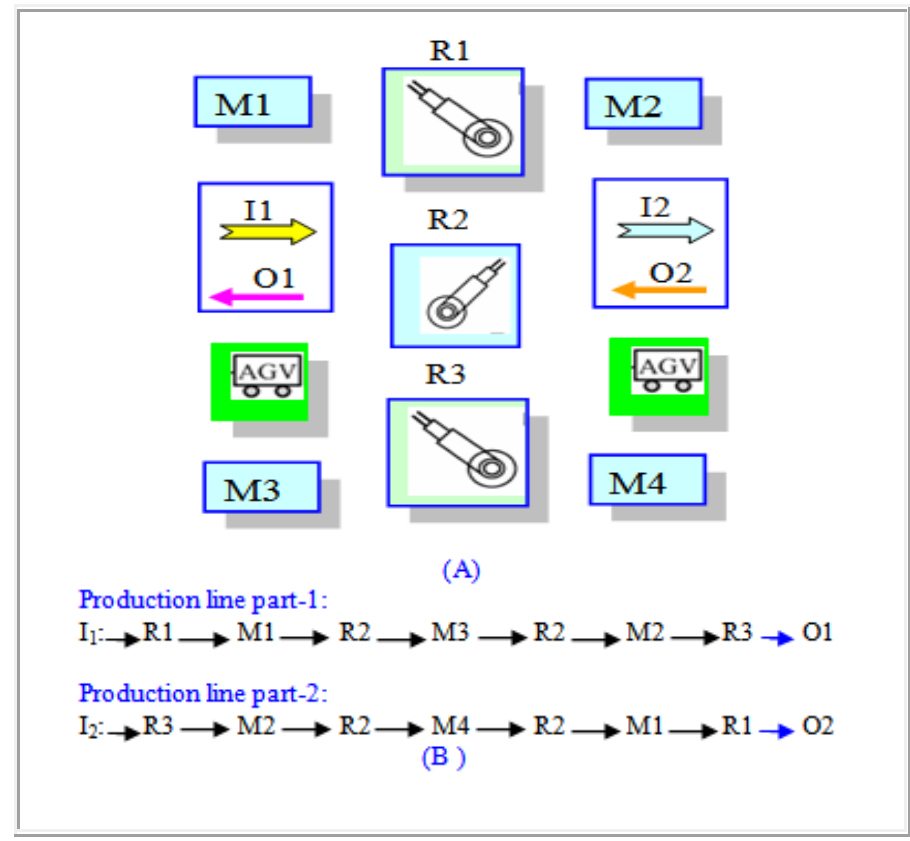

Fig. 5. (A). Production layout, and (B) Production Line

The Reachability Graph Results has 839 status.

The elementary siphons (ESs) are an identification algorithm proposed in [17], where $\Pi_{E}=\left(S_{1}, S_{2}, S_{3}\right)$ are a set of elementary siphons and $\breve{\mathrm{S}}_{4}-\breve{\mathrm{S}}_{15}$ are dependent ones. However, the assignment to ESs that have been thoroughly investigated up in [18], and a subnet to the same net leads to obtain the control system. For this example system, we have three the SMSs: $S_{1}, S_{2}, S_{3}$ are depending on the elementary algorithm described in $[17,18]$ such as:

$$
\begin{gathered}
\lambda_{\mathrm{S} 1}=p_{2}+p_{5}+M 1+M 4+R 1+R 2 ; \\
\lambda_{\mathrm{S} 2}=p_{6}+p_{9}+M 2+M 3+R 2+R 3 ; \text { and }
\end{gathered}
$$




$$
\lambda_{\mathrm{S} 3}=p_{2}+p_{3}+p_{7}+M 1+M 2+R 1 .
$$

From matrix [ๆ], we can compute as:

$$
\eta_{\mathrm{S} 3}=\eta_{\mathrm{S} 1}+\eta_{\mathrm{s} 2}
$$

The characterization of T-vector matrix is as follows:

$$
\dot{\eta}_{S 1}=-t_{1}+t_{5}-t_{7}+t_{8}, \quad \dot{\eta}_{S 2}=-t_{1}+t_{3}-t_{8}+t_{11} \text {, and } \dot{\eta}_{S 3}=-2 t_{1}+t_{3}+t_{5}-t_{7}+t_{11} \text {. }
$$

These procedures given in Table 1 , it is straightforward to denote essentially $\lambda_{\mathrm{S} 3}=\lambda_{\mathrm{S} 1}+\lambda_{\mathrm{S} 2}$. It should be mentioned, that are two ESs $S_{1}$, and $S_{2}$, and $S_{3}$ are dependent siphons one.

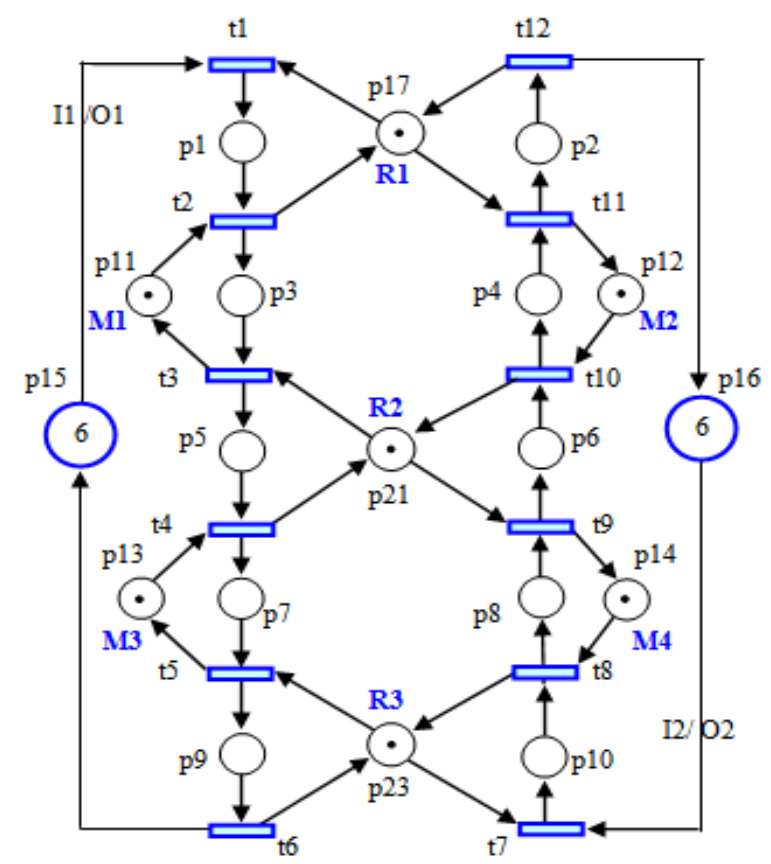

Fig. 6. A marked $\mathrm{S}^{3} \mathrm{PR}\left(\mathrm{G}, M_{0}\right)$ for Fig. 5 .

Table 1. The reconfiguration of T-vector matrix is as follows:

\begin{tabular}{|l|l|l|l|l|l|l|l|l|l|l|l|l|l|l||}
\hline & $\mathrm{I}$ & $\mathrm{t}_{1}$ & $\mathrm{t}_{2}$ & $\mathrm{t}_{3}$ & $\mathrm{t}_{4}$ & $\mathrm{t}_{5}$ & $\mathrm{t}_{6}$ & $\mathrm{t}_{7}$ & $\mathrm{t}_{8}$ & $\mathrm{t}_{9}$ & $\mathrm{t}_{10}$ & $\mathrm{t}_{11}$ & $\mathrm{t}_{12}$ & $\mathrm{I}$ \\
\hline$\eta_{\mathrm{S} 1}=$ & $\mathrm{I}$ & -1 & 0 & 0 & 0 & 1 & 0 & -1 & 1 & 0 & 0 & 0 & 0 & $\mathrm{I}$ \\
\hline$\eta_{\mathrm{S} 2}=$ & $\mathrm{I}$ & -1 & 0 & 1 & 0 & 0 & 0 & 0 & -1 & 0 & 0 & 1 & 0 & $\mathrm{I}$ \\
\hline$\eta_{\mathrm{S} 3}=$ & $\mathrm{I}$ & -2 & 0 & 1 & 0 & 1 & 0 & -1 & 0 & 0 & 0 & 1 & 0 & $\mathrm{I}+$ \\
\hline
\end{tabular}

The rows of the above matrix have presented the syntheses control transition net according to Definition 7. Three monitors are required, where T-vector values of $S_{1}, S_{2}$, and $S_{3}$ in Fig. 6, are implying. The simulation module computes the resources are associated with the nine sets of P-Semifiows: 


$$
\begin{gathered}
\mathrm{I}_{\mathrm{p} 15}=\mathrm{p}_{1}+\mathrm{p}_{3}+\mathrm{p}_{5}+\mathrm{p}_{7}+\mathrm{p}_{9}+\mathrm{p}_{15} \text {, and } \\
\mathrm{I}_{\mathrm{p} 16}=\mathrm{p}_{2}+\mathrm{p}_{4}+\mathrm{p}_{6}+\mathrm{p}_{8}+\mathrm{p}_{10}+\mathrm{p}_{16}
\end{gathered}
$$

are the minimal P-Semifiows associated with idle places $\mathrm{p}_{15}$ and $\mathrm{p}_{16}$. Likewise, $\mathrm{I}_{\mathrm{R} 1}=\mathrm{p}_{1}+\mathrm{p}_{2}+\mathrm{R} 1$, where $\mathrm{M}_{0}(\mathrm{R} 1)$ $=1$;

$$
\begin{gathered}
I_{R 2}=p_{5}+p_{6}+R 2 \text {, where } M_{0}(R 2)=1 ; \\
I_{R 3}=p_{9}+p_{10}+R 3 \text {, where } M_{0}(R 3)=1 ; \quad I_{M 1}=p_{3}+M 1 \text {, where } M_{0}(M 1)=1 ; \\
I_{M 2}=p_{7}+M 2 \text {, where } M_{0}(M 2)=1 ; I_{M 3}=p_{8}+M 3 \text {, where } M_{0}(M 3)=1 ; \text { and } \\
I_{M 4}=p_{4}+M 4 \text {, where } M_{0}(M 4)=1
\end{gathered}
$$

are the minimal P-Semifiows associated with resources $R 1, R 2, R 3, M 1, M 2, M 3$, and $M 4$, respectively.

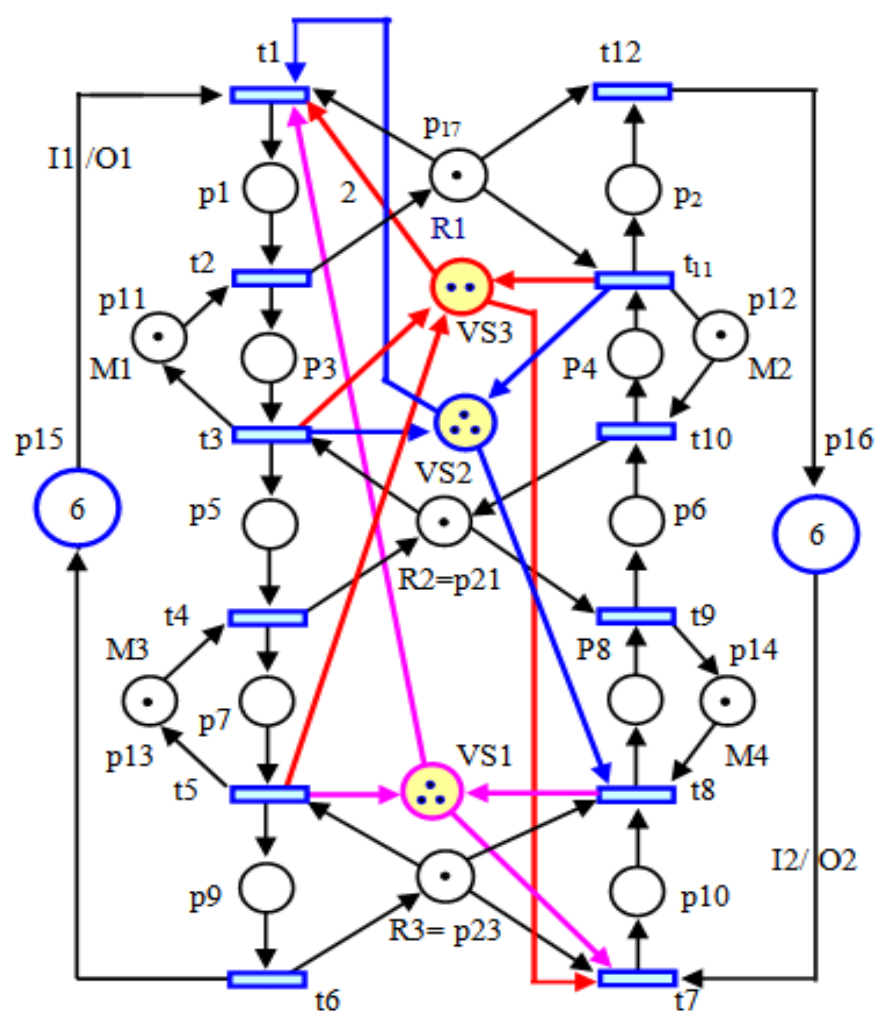

Fig. 7. $P N$ model control system $\left(G_{1}, M_{1}\right)$ 
Siphon based control (SC) to the final resents subnet based on reachability graph-based control (RGC) is generally more convoluted than the one utilizing SC strategies. It should be mentioned, that RGC had 49 status i.e., circuit of net, and the consequence is liveness net shown in Fig. 8, is checking in the PN-Matlab [26]. Among the existing modelling formalisms, PNs perfect reachable states are the utilization of all add monitors regards to resource places. With regard to the control places of $\mathrm{VS}_{1}-\mathrm{VS}_{3}$, are necessary to add, and the resulting net is deadlock-free condition. The interactions between resources, activities, and the flow of processes can be represented by simulation Petri_Net and structural models according to the sequences of events.

There are three minimal P-Semifiows associated with control places taken from Fig. 7, as follows:

$\mathrm{I}_{1}=\left(1,0,1,0,1,0,1,0,0,1, \mathrm{VS}_{1}\right)$ is the minimal P-Semifiows associated with control place $\mathrm{VS}_{1}$ of the resultant net $\left(G_{1}, M_{1}\right)$. Therefore, $\mathrm{I}_{1} \cdot \mathrm{M}_{1}=0$ by Definition 1, and Proposition 3, we can obtain the control place $\mathrm{VS}_{1}$ from that: $\left[\mathrm{G}_{1}\right]\left(\mathrm{VS}_{1}, \mathrm{t}\right)=-\mathrm{t}_{1}+\mathrm{t}_{5}-\mathrm{t}_{7}+\mathrm{t}_{6}$. Where $M_{1}\left(\mathrm{VS}_{1}\right)=M_{0}\left(\mathrm{~S}_{1}\right)-1=4-1=3$.

In a similar way, for $\mathrm{I}_{2}=\left(1,0,1,1,0,1,0,1,0,0, \mathrm{VS}_{2}\right)$ is the minimal P-Semifiows associated with control place $\mathrm{VS}_{2}$ of the resultant net $\left(\mathrm{G}_{1}, \mathrm{M}_{1}\right)$. Subsequently, $\mathrm{I}_{2} \cdot \mathrm{M}_{1}=0$ by Definition 1 , and Proposition 3 , we can obtain the control place $\mathrm{VS}_{2}$ from that: $\left[\mathrm{G}_{1}\right]\left(\mathrm{VS}_{2}, \mathrm{t}\right)=-\mathrm{t}_{1}+\mathrm{t}_{3}-\mathrm{t}_{8}+\mathrm{t}_{11}$, where $\mathrm{M}_{1}\left(\mathrm{VS}_{2}\right)=\mathrm{M}_{0}\left(\mathrm{~S}_{2}\right)-1=4-1=3$.

Likewise, for $\mathrm{I}_{3}=\left(2,0,2,1,1,1,1,1,0,1, \mathrm{VS}_{3}\right)$ is the minimal P-Semifiows associated with control place $\mathrm{VS}_{3}$ of the resultant net $\left(G_{1}, M_{1}\right)$. Therefore, $I_{3} \cdot M_{1}=0$ by Definition 1 , and Proposition 3, we obtain the control place $\mathrm{VS}_{3}$ from that: $\left[\mathrm{G}_{1}\right]\left(\mathrm{VS}_{3}, \mathrm{t}\right)=-2 \mathrm{t}_{1}+\mathrm{t}_{3}+\mathrm{t}_{5}-\mathrm{t}_{7}+\mathrm{t}_{11}$, and $\mathrm{M}_{1}\left(\mathrm{VS}_{3}\right)=\mathrm{M}_{0}\left(\mathrm{~S}_{3}\right)-1=3-1=2$.

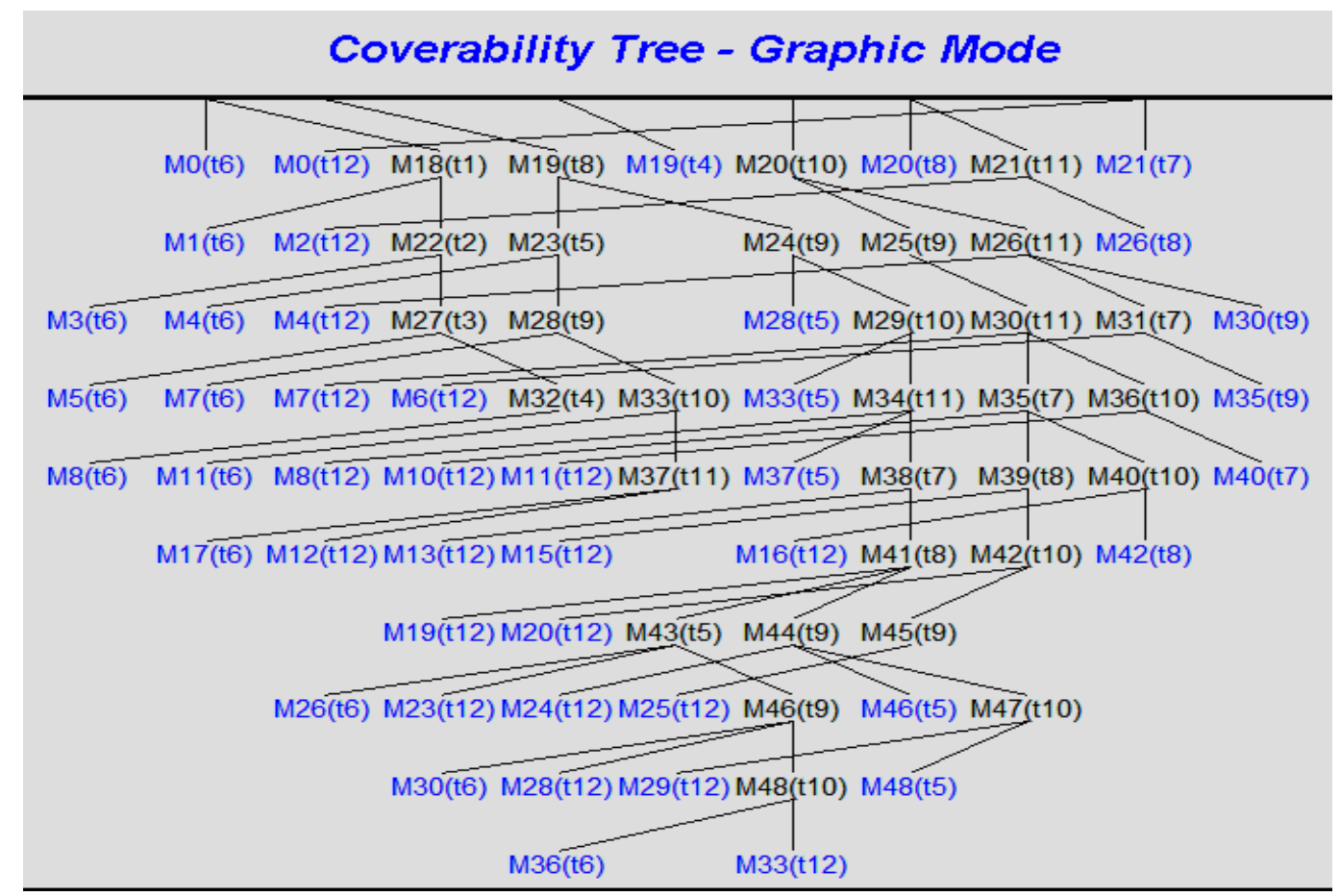

Fig. 8. Segment of Coverability tree Graphic is running under untime PN in [26] controller net referring to Fig 7.

This method gives an analytical solution to the $\mathrm{S}^{3} \mathrm{PR}$ steady state in case of adding $\mathrm{VS}_{1}, \mathrm{VS}_{2}$ and $\mathrm{VS}_{3}$ to $\left(G_{1}\right.$, $\left.M_{1}\right)$, where the new model $\left(G_{1}, M_{1}\right)$ is generating the liveness processes execution, and the RG has 49 states that are used the PN toolbox with MATLAB [26], as shown in Fig. 8. The PN toolbox contains a function, draw PN, to assist the user in inputting the PN system and obtaining the Reachability Graph. 


\section{Conclusion}

This paper describes the approaches based efficiencies elementary siphon to the computation of the deadlock problem with an $S^{3}$ PRs net compliant with typical FMSs. An effective deadlock prevention policy is proposed to a class of Petri net models appearing in the modelling and control of manufacturing systems. A special class of siphon Petri nets called $S^{3} P R$ net is used to specify independent models for the system structure and the work plans. The experimental results are shown three approaches presentations of the Petri Net effective by the structural analysis, reachability graph analyses, and simulation behaviours using Petri Net-Toolbox for Matlab [26] is also covered in detail in order to visualized the solutions for both of PN, and deadlock prevention in FMS. We have presented an approach from P-Semifiow is used to add a monitor to every minimal siphon that can be emptied and to ensure that any outgoing arc of the monitors will point to source transition. Future work should extend the well-suited analytical strength of PN tools for frequent deadlock reconfigurable through simulation, and then apply it to an FMS, possibly integrated with suitable simulation packages.

\section{References}

[1] Banaszak Z., and M. H. Abdul-Hussin, "Modelling and Simulation of Flexible Assembly System: A Petri Net Approach," in: Qater University of Sciences Journal, Vol. 15, No. 2, (1995), pp. 307-318 https://qspace.qu.edu.qa/handle/10576/10172

[2] Banaszak Z., M.H. Abdul-Hussin, "Petri Net Approach to Automatic Real-time Program Synthesis," , In: Control and Cybernetics, Vol. 17, No. 4, pp: 361-375, 1988, Poland

[3] Banaszak A.Z., \& M. H. Abdul-Hussin, "Planning of Robots Cooperation: Automatic Modelling and Control", In: Engineering and Technology Journal, Published by University of Technology, Baghdad, Vol. 18, No.1, (1999), pages 42- 65. ISSN: 1681690024120758 Download: https://drive.google.com/file/d/1XshYkn2caNPnVCMSoYxlR1rCqYFZ3SMY/view

[4] Banaszak Z., \& M.H. Abdul-Hussin, "Algorithm of Live and Conflict-free Petri Net Synthesis for Prescribed System Performance," in: Engineering \& Technology Journal, Baghdad, Vol. 17, No. 2, 1988, pp. 154-173, ISSN: $16816900 \quad 24120758$ Download: https://drive.google.com/file/d/1Bkqsw_IxJC6QHE4jT2KZrWWOvxAz4BHG/view

[5] Abdul-Hussin M.H., "Synchronization Competitive Processes of Flexible Manufacturing Systems Using Siphons Petri Net," in: Proc. of IEEE 5th National Symposium on information technology: towards new smart world, (2015), Riyadh, Saudi Arabia, pp.1-6. DOI: 10.1109/NSITNSW.2015.7176395

[6] Abdul-Hussin M.H., "Design of a Petri net based Deadlock Prevention policy supervisor for S3PR," Proceeding of IEEE 6th International Conference on Intelligent systems, modelling \& simulation, Kuala Lumpur, (2015), Malaysia, pp.46-52. DOI: 10.1109/ISMS.2015.54

[7] Abdul-Hussin M.H., "Petri Nets approach to simulate and control of Flexible Manufacturing Systems, " in: International Journal of Software Engineering (IJSE), Vol.1, 2014, pp.16-25 https://citeseerx.ist.psu.edu/viewdoc/summary?doi=10.1.1.673.4360\&rank=1

[8] Arm J., Z. Bradac, O. Bastan, J. Streit, S. Misik, "Design pattern for the runtime model-based checking of a real-time embedded system," in IFAC-Papers OnLine 52, no. 27 (2019): pp.127-132.

[9] Abdul-Hussin M.H., \& Z. Banaszak, "On liveness and a class of generalized Petri nets,", in: Proceeding of IEEE 8th Annual Industrial Automation and Electronic Engineering Conference (IEMECON), Bangkok, Thailand,(2017), pages 257-267. DOI :10.1109/iemecon.2017.8079601

[10] Abdul-Hussin M.H., \& Z. Banaszak, "Siphon based deadlock prevention for a class of S4PR genera-lized Petri nets," in Proceeding of IEEE International conference on control, automation and information science (ICCAIS), (2017), Chiang Mai, Thailand, pp. 239-244 DOI:10.1109/ICCAIS.2017.8217583 
[11] Abdul-Hussin M.H., "On Structural Conditions of $S^{3} P R$ based Siphon to Prevent Deadlocks of Manufacturing Systems," International Journal of Simulation, Systems, Science. \& Technology, (IJSSST), (2016), Vol. 17, no. 33, pp. 32.1-32.8, DOI: 10.5013/IJSSST.a.17.33.32

[12] Abdul-Hussin M.H., "Elementary Siphons of Petri Nets and Deadlock Control in FMS," Journal Computer \& Communications (JCC), Vol. 3, No. 7, (2015), PP. 1-12. DOI: 10.4236/jcc.2015.37001

[13] Abdul-Hussin M.H., "Utilization Elementary Siphons of Petri Net to Solved Deadlocks in Flexible Manufacturing Systems.”, International Journal of Scientific \& Engineering Research (ijser), (Vol. 6, Issue 7, July 2015), PP. 1611-1619, DOI: 10.14299/ijser.2015.07.006

[14] Row T., W-M Syu, Y-L Pan, \& C-C. Wang, "One Novel and Optimal Deadlock Recovery Policy for Flexible Manufacturing Systms Using Iterative Control Transitions Strategy,", in: Mathematical Problems in Engineering, Hindawi, Vol. 2019, PP. 1-12

[15] Ezpeleta J., J.M. Colom, and J. Martinez, "A Petri net based deadlock prevention policy for flexible manufacturing systems,", IEEE Trans. Robotics and Automation, 11, (2): 173-184, (1995).

[16] Li X., et.al., "Elementary Siphon-Based Robust Control for Automated Manufacturing Systems With Multiple Unreliable Resources,", IEEE Access, Vol. 7, (2019), pp. 21006-21019

[17] Li Z.W., and M. C. Zhou, "Elementary siphons of Petri nets and their application to deadlock prevention in flexible manufacturing systems," IEEE Trans. System Man Cybernetic Part A-System Hum., Vol.34, No. 1, pp. 38-51, 2004

[18] Li Z.W., \& Zhou M.C., "Control of elementary and dependent siphons in Petri nets and their application," In: IEEE Transaction System Man, Cybernetic, Part A, Humans, (2008), Vol.38, no. 1, pp. 133-148

[19] Guo X., S.G. Wang, D.You, Z. Li, \& X. Jiang, “A Siphon-based deadlock Prevention strategy for S PR," IEEE-Access, (2019), Vol. 7, PP. 86863-86873.

[20] Abdul-Hussin M.H., "Computation minimal siphons for a class of generalized Petri nets,", In: Proceedings of the 8th International Conference on Intelligent Systems, Modelling and Simulation, Kuala Lumpur, Malaysia, 2018, PP.49-57. DOI: 10.1109/ISMS.2018.00019

[21] Abdul-Hussin M.H., "Supervision deadlock prevention of FMSs using a class of Petri Nets-S4PR,", Proc. of IEEE-9th Annual Information Technology, Electromechanical Engineering \& Microelectronics Conference (IEMECON 2019), Jaipur, India, 2019, $\quad$ PP. 273 - 278. DOI: 10.1109/IEMECONX.2019.8877010

[22] Zhuang Q., W. Dai, S. Wang, J. D.Q. Tian, "An MIP-based deadlock prevention policy for siphon control,", IEEE Access, Vol. 7, (2019) pp. 153782-153790

[23] Abdul-Hussin M.H., "Simulation and Control of Manufacturing System Based Siphon Petri Nets,", International Journal of Simulation, Systems, Science \& Technology, (IJSSST), (2019), Vol. 20, No.4, pp.21.1-12.7, http://ijssst.info/Vol-20/No-4/paper12.pdf

[24] Abdul-Hussin M.H., "Flexible Manufacturing System Design and Optimization using Petri net-based Elementary Siphons,", International Journal of Computer Applications (2015), Vol.119, No. 22., pp.1926, doi:10.5120/21369-4408

[25] You D., S. G. Wang, W. Z. Dai, et al., "An approach for enumerating minimal siphons in a subclass of Petri nets," IEEE Access, vol. 6, pp. 4255 - 4265, Oct. 2018.

[26] Pastravanu O., M.-H. Matcovschi, and Cristian Mahulea, "Petri Net Toolbox-Teaching Discrete Event Systems Under MATLAB," In Advances in Automatic Control, pp. 247-255. Springer, (2004), http://www.pntool.ac.tuiasi.ro/

[27] Zhao M.; and Y. Hou, "An iterative method for synthesizing non-blocking supervisors for a class of generalized petri nets using mathematical programming," Discrete Event Dynamic Systems, vol. 23, no. 1, pp. 3-26, 2013

[28] Zhao, M.; Uzam M., "A suboptimal deadlock control policy for designing non-blocking supervisors in flexible manufacturing systems, Information Science, 2017, 388, pp135-153

[29] Hou Y.F., and Kamel Barkaoui, “ Deadlock analysis and control based on Petri nets: A siphon approach review," Advances in Mechanical Engineering, 2017, Vol. 9(5) 1-30 
[30] Abdul-Hussin M. H., "An S ${ }^{4} P R$ Class Petri Net Supervisor for Manufacturing System," International Journal of Simulation Systems Science \& Technology, (IJSSST), Vol. 17, no.33, 2016, PP. 31.1-31.11

\section{Authors' Profiles}

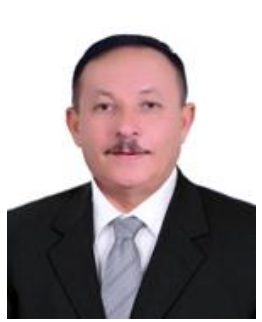

Mowafak Hassan Abdul-Hussin received the B.S. (1977) from the Al-Mustansiriyah University Baghdad and M.S., and Ph.D. degrees from the Technical University of Wroclaw, Poland, 1984, and 1989 respectively. From 1991, he is currently an Assistant Professor of computer science with the University of Technology in Baghdad. His research interests include Petri net theory and applications, supervisory control automated manufacturing systems.

How to cite this paper: Mowafak Hassan Abdul-Hussin, " Modelling Manufacturing System Controller-based Siphon Petri Nets ", International Journal of Wireless and Microwave Technologies(IJWMT), Vol.10, No.3, pp. 17-31, 2020.DOI: $10.5815 /$ ijwmt.2020.03.02 